\title{
Studies on the Measurement of Unpleasant Events and Relations with Depression
}

\author{
Peter M. Lewinsohn and Joseph Talkington \\ University of Oregon
}

The goal was to construct a psychometrically sound instrument for the measurement of aversive events. Hypotheses about the occurrence of aversive events and depression were also tested. The Unpleasant Events Schedule (UES) consists of 320 events generated by an extensive search of events experienced as distressing by many people. Each event was rated for frequency of occurrence (3-point scale) during the past month and for subjective aversiveness (3-point scale). The events were categorized into seven rational scales (Health and Welfare, Achievement-Academic-Job, Domestic Inconveniences, Sex-Marital-Friendship, MaterialFinancial, and Social Exits). The UES was tested on a group $(N=202)$ about equally divided between depressed patients and two non-depressed control groups. The depressed patients were selected using the MMPI and a clinical interview. A normal MMPI control group was selected on the basis of MMPI scores in the normal range and no history of depression. A second control group (High-MMPI Controls) was selected on the basis of elevations on clinical MMPI scales other than depression and no history of depression. The UES was found to have very high internal consistency and adequate test-retest repeatability. Construct validity was investigated with comparisons between depressed and non-depressed groups and by the covariation between changes in the rate of occurrence of aversive events and changes in depression level. The UES should prove useful in future research on quantitative relationships between stressful life events and psychopathology.

APPLIED PSYCHOLOGICAL MEASUREMENT

Vol. 3, No. 1 Winter 1979 pp. 83-101

() Copyright 1979 West Publishing Co.
The study of the relation between stressful life events and the occurrence of disease and mental disorder has a long history of active and sustained research investigation (e.g., Dohrenwend \& Dohrenwend, 1974; Gunderson \& Rahe, 1974; Hurst, Jenkins, \& Rose, 1976; Rabkin \& Struening, 1976). The major goal of this research has been to demonstrate a temporal association between the onset of pathology and a recent increase in the number of stressful life events.

This area of investigation was given considerable impetus by the successful quantification of stressful life events with the Schedule of Recent Experience (Hawkins, Davies, \& Holmes, 1957; Holmes \& Rahe, 1967; Rahe, Meyer, Smith, Kjaer, \& Holmes, 1964). The original scale consisted of 43 items intended to represent fairly common events arising from family, personal, occupational, and financial situations that required or signified change in ongoing adjustments. Two types of items were used: life events, occurrences that involve the individual (e.g., the death of the spouse); and items indicative of the life style of the individual (e.g., change in eating habits). The occurrence of the events during the preceding six months was checked and scores on the first version consisted of the number of events that had occurred. Subsequently, weights were assigned to each item based on ratings by a sample of judges (Holmes \& Rahe, 1967). The judges were asked to rate the life events as to the 
relative amount of life change and readjustment necessary to accommodate to the events. The resultant mean scores were referred to as Life Change Units (Rahe, McKean, \& Arthur, 1967), and the listing of the life change events by rank order of their mean Life Change Unit scores was called the Social Readjustment Rating Scale (SRRS). Many investigators working in this field have used the original or modified versions of the SRRS.

There are a number of serious methodological and conceptual problems which limit the potential clinical usefulness and theoretical interpretation of results obtained with the SRRS (Rabkin \& Struening, 1976). Conceptually, the SRRS is closely tied to the Holmes and Rahe definition of stress as the experience of an accumulation of life events which require adaptation and change. According to this formulation, the direction of such changes is not important, only their magnitude. However, more recent research (Gersten, Langer, Ersenberg, \& Orzek, 1974; Vinokur \& Selzer, 1975) suggests that the predictive power of the SRRS is a function of only the undesirable items on the schedule and that the cumulative occurrence of desirable life events does not increase the probability of disorder. Since many of the items refer to symptoms and to potential consequences of illness (e.g., change in sleeping habits, revision of personal habits, trouble with boss, change in number of arguments with spouse), the events may be prodromal (i.e., early manifestations of disorder) rather than antecedent (Hudgens, Morrison, \& Brachha, 1967). The items also selectively emphasize events of young adulthood (e.g., begin or end school, marriage, gain of new family member). Typically, young adults report twice as many life changes as those over 60 (Dekker \& Webb, 1974; Uhlenhuth, Lipman, Balter, \& Stern, 1974). It is unclear, however, whether this finding is due to the character of the scale or to greater degrees of stress in early adulthood. The assignment of constant weights to the items, based on strong convergence by the standardization judges regarding the appropriate weights for particular items, nevertheless as- sumes that events are equally stressful for everyone.

The purpose of the present investigation was to construct a psychometrically sound instrument (the Unpleasant Events Schedule) for the measurement of aversive ${ }^{1}$ (unpleasant) events. It was assumed that there exists a large universe of events, consisting of stimuli (e.g., electric shock); situations (e.g., arguments with spouse, separations); and behaviors (e.g., cleaning up a mess), which are experienced as aversive (unpleasant, painful, noxious, or distressing) by the individuals to whom they occur. It was therefore deemed important that this universe be adequately sampled. It was also assumed that there are important and consistent individual differences, not only in the rate of occurrence of events, but also in their subjective impact. Hence, it was felt important that the instrument measure not only the occurrence but also the experienced aversiveness of events.

The relation between the occurrence of aversive events and clinical depression was also of interest. Three questions were of concern:

1. Are the rate of occurrence and the subjective aversiveness of unpleasant events elevated in depressed individuals?

2. Are certain kinds of aversive events uniquely associated with the occurrence of depression?

3. Do depressives differentiated on the endogenous and reactive dimensions (Lewinsohn, Zeiss, Zeiss, \& Haller, 1977) differ in rate of occurrence of aversive life events?

\section{METHOD}

\section{Phase I}

\section{Unpleasant Events Schedule: Form I}

Item Generation. In order to generate a large and comprehensive list of events consid-

'The words aversive and unpleasant are used interchangeably in this paper. It is assumed that individuals are motivated to avoid or to terminate aversive events. 
ered to be unpleasant by many people, items were generated in two different ways. First, a short survey ${ }^{2}$ was mailed to a heterogeneous group of 390 persons who had participated in previous studies. These participants were asked to list nine events which had happened to them, selecting three which had been very unpleasant, three which had been moderately unpleasant, and three which had only been slightly unpleasant. One hundred fifty surveys were received. Second, a group of 24 subjects stratified by age (20-39, 40-59, 60 and older) and sex were asked to self-monitor unpleasant events which happened to them during a seven-day period. The items from the two sources were grouped into seven initial "key word" categories (e.g., accidents, legal, financial). Items were eliminated on the basis of three criteria: (1) redundancy; (2) having only cognitive components (e.g., worrying, thinking about death); and (3) symptoms (e.g., insomnia, attempting suicide). From the resulting pool, 320 items were selected to constitute UES Form I.

Administration. The instructions for the Unpleasant Events Schedule call for two responses to each item. The first response rates its frequency of occurrence during the past month on a 3-point scale:

1. This has not happened in the past 30 days;

2. This has happened a few (1-6) times in the past 30 days;

3. This has happened often (7 or more times) in the past 30 days.

The second response rates its subjective aversiveness on 3-point scale:

1. This was not unpleasant;

2. This was somewhat unpleasant;

3. This was very unpleasant.

Since one of the objectives was to be able to identify potentially aversive events, the respond-

\footnotetext{
${ }^{2}$ These and other materials will be sent upon request.
}

ent is asked to give a subjective aversiveness rating for each event, whether or not it has actually been experienced during the past 30 days.

Three scores are computed:

1. A mean frequency score, which is assumed to reflect the rate of occurrence of the events;

2. A mean aversiveness score, which is assumed to reflect the potential for aversive experience;

3. A mean cross-product score (frequency rating $\times$ aversiveness rating), which is assumed to reflect the total amount of aversiveness experienced during the preceding month. A multiplicative function was chosen so that a response of either zero frequency or no aversiveness would yield a zero-experienced aversiveness score.

Administration time of the UES, Form I, is approximately one hour.

Scale generation. The item generation process suggested the following rational scales:

Scale 01-Health and Well-Being. Items involving injury, pain, and danger to self or to important others ( 37 items).

Scale 02-Achievement-Academic-Job. Items involving work, school, and other competitive situations; achievement-related failures, disappointments, and difficulties ( 30 items).

Scale 03-Domestic, Day-to-Day Inconveniences. Items involving noise, crowding, minor physical discomforts, mishaps, delays, and accidents ( 27 items).

Scale 04-Sexual, Marital, Friendship. Items involving rejection, separation, and other disappointing and painful interpersonal events (22 items).

Scale 05-Legal. Items involving encounters with the police, courts of law, lawsuits, incarceration, and so forth (10 items).

Scale 06-Material-Financial. Items involving financial problems and losses ( 26 items). 
The above-mentioned scales were generated by three judges working independently and using the above-mentioned definitions. The judges examined each item with the instruction that they rate it for one of the six scales if it clearly met the definition for that scale. These scales thus have no overlapping items. Items were assigned to the respective scales only when at least two of the three judges agreed on the categorization for the item.

Two additional scales were constructed:

Scale 07-Social Exits. Items which clearly involved departures from the social field of the subject (i. e., death of a close family member, separation, divorce, family member leaves home, child marries, and men drafted [Paykel, Myers, Dienelt, Klerman, Lindenthal, \& Pepper, 1969]). For this scale, the judges reviewed the total item pool a second time, selecting items which met the "social exits" definition regardless of whether the item had already been assigned to another scale (6 items).

Scale 08-Most Discriminating Items. The UES was administered to two consecutive cohorts of people $(N=150$ and $N=61)$ about equally divided among depressed, non-depressed high-MMPI, and normal controls. (Details on selection criteria are given below.) On the basis of chi-square analyses of each item (using the cross-products score) for the first cohort, items on which the depressed group attained the highest score $(p<.01)$ were selected. Forty items met this criterion. Twenty-seven of these were cross-validated with the second cohort and were used to constitute a "most discriminating items" scale.

\section{Participants}

Seventy-six depressed patients receiving treatment at the University of Oregon Psychology Clinic, 61 high-MMPI controls, and 74 normal controls participated in this study. Potential depressed subjects were recruited by announc- ing, through both public media and community agencies, the availability of a depression treatment program. Non-depressed controls were recruited by advertising an opportunity to earn a minimum of $\$ 20$ for participating in a psychological research project.

A two-stage screening process, involving cutoff scores on selected MMPI scales and interviewer ratings on the depression factors identified by Grinker, Miller, Sabshin, Nunn, and Nunnally (1961), was used in selecting three subject groups: depressed, high-MMPI control, and normal control. The criteria for selection are shown in Table 1. Mean MMPI $D$ scale values ( $T$ scores) for the three groups were 89.0, 57.5, and 50.5 , respectively.

The second stage of screening involved interviews conducted by members of the project staff. On the basis of these interviews, subjects were rated on 25 items of the Feelings and Concerns Checklist developed by Grinker et al. (1961). The items represent the most common symptoms of depression, and each was rated on a 4point scale $(0=$ not present; $3=$ present to a marked extent). Satisfactory inter-rater reliability for individual items (average $r=.69$ ) was reported for 30 subjects in a previous study (MacPhillamy \& Lewinsohn, 1974). On the basis of these ratings, scores were computed on four of the depression factors identified by Grinker et al. (1961): (1) Dysphoria, (2) Material Burden, (3) Guilt, and (4) Loneliness/Unloved. Mean scores on Factor I (Dysphoria) for the three groups were $1.56, .10$, and .04 , respectively.

Previous experience has indicated that the two-stage depression criteria identify persons in whom depression is present to a clinically significant degree and for whom being depressed constitutes the major presenting psychopathology (Lewinsohn, Biglan, \& Zeiss, 1976). The present sample of depressives may be considered predominantly neurotic and unipolar, with severity level ranging from moderate to severe. To assess the endogenous-reactive dimension, the interviewers also rated each participant on an additional 10 symptoms which were selected 


\section{Table 1 \\ Classification Procedure for Selecting Depressed and Nondepressed Subjects}

\begin{tabular}{|c|c|c|}
\hline \multicolumn{3}{|c|}{ Classification Criteria } \\
\hline Group & Step 1: MMPI & $\begin{array}{ll}\text { Step 2: } & \begin{array}{l}\text { Grinker Interview } \\
\text { Rating }\end{array} \\
\end{array}$ \\
\hline Depressed & 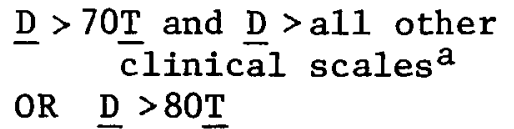 & $\begin{array}{l}\text { Factor I (Dysphoria) } \geq 1.0 \\
\text { Mean factor score } \geq .70\end{array}$ \\
\hline $\begin{array}{l}\text { High-MMPI } \\
\text { Control }\end{array}$ & 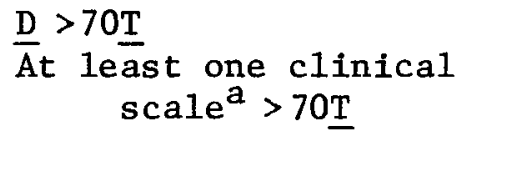 & $\begin{array}{l}\text { Factor I (Dysphoria) }<.70 \\
\mathrm{~S} \text { rated as having no current or } \\
\text { major past problems with } \\
\text { depression. }\end{array}$ \\
\hline $\begin{array}{l}\text { Normal } \\
\text { Control }\end{array}$ & $\begin{array}{l}\frac{\mathrm{L}}{\mathrm{A}}<60 \mathrm{~T} \\
\quad<.70 \mathrm{~T}\end{array}$ & $\begin{array}{l}\text { Mean factor score }<.35 \\
\text { No factor score }>.70 \\
S \text { rated as having no current } \\
\text { or major past problems with } \\
\text { depression. }\end{array}$ \\
\hline
\end{tabular}

a Clinical scales did not include $\underline{\mathrm{L}}, \underline{\mathrm{K}}, \underline{\mathrm{Mf}}, \underline{\mathrm{Ma}}$, and $\underline{\mathrm{Si}}$.

because they have consistently loaded on endogenous-reactive factors in prior factor analytic studies of depressive symptomatology (Mendels $\&$ Cochrane, 1968). The method used for categorizing the depressed subjects into endogenous and reactive subgroups was based on the results of an earlier factor analytic study (Lewinsohn et al., 1977) with three separate depressed samples, in which endogeneity and reactivity had emerged as independent and orthogonal dimensions.

A mean endogeneity score was computed for each depressed participant based on his/her ratings on symptoms consistently loading on the endogeneity factor: (1) lacking in reactivity to environmental stimuli; (2) showing no interest in life; (3) retarded, i.e., slow, feeling tired; (4) feeling unable to act; (5) considering self lazy; (6) feeling helpless and powerless; and (7) perceiving depression as qualitatively different from ordinary sadness. A mean reactivity score was computed for each depressed participant based on his/her ratings on symptoms consistently loading on the reactivity factor: (1) feeling that he or she is bearing troubles, (2) presence of precipitating stress, (3) crediting problems to excessive family and/or job responsibilities, (4) expressing concern for welfare of family or friends, (5) having visceral symptoms, (6) feeling at "end of rope", (7) having middle-of-the-night insomnia, and (8) showing self-pity. Using median splits, the depressives were categorized into high-high, low-high, high-low, and low-low subgroups on the endogeneity and reactivity factors.

The depressives were assigned randomly to one of three treatments, described in detail elsewhere: (1) Interpersonal Treatment (Zeiss, 1977), (2) Cognitive Treatment (Munoz, 1977), and (3) Pleasant Activities Treatment (Lewinsohn, 1975). Depression level was assessed on the basis of the MMPI $D$ scale at three monthly assessment periods (T2, T3, and T4) following the initial assessment (T1). On the basis of residual change scores on the MMPI $D$ scale from T1 to T4, depressives were dichotomized into more and less improved subgroups. Mean $D$ 
scale scores changed from 88.1 (T1) to 52.6 (T4) for the more improved depressives and from 89.6 to 79.4 for the less improved depressives.

The mean ages for the three diagnostic groups were: depressed-33.9; high-MMPI control-25.7; and normal control-29.9. The percentage of each group comprised of females was $68.0,58.0$, and 51.3 , respectively.

All participants completed the Unpleasant Events Schedule at the initial assessment (T1). The depressed subjects and, due to financial considerations, only a randomly selected subset of high-MMPI controls and normals $(N=21$ and $N=25$, respectively) completed the Unpleasant Events Schedule at three successive monithiy intervals (T2, T3, and T4).

Social Readjustment Rating Scale. On the basis of the initial interview, the interviewer checked which of the events $(K=43)$ of the Social Readjustment Rating Scale (Holmes \& Rahe, 1967) had occurred in the subject's life within the last six months, indicating how many months ago it had occurred. Events which had occurred, but which could not be dated precisely, were also checked. A total Life Change Units score, based on all the events that had occurred during the preceding six months and during the preceding month, and a weighted score based on the Social Exits items used by Paykel et al. (1969), was computed for each subject.

\section{Phase II}

Between three to six months after the final assessment (T4), 58 of the participants were recontacted and asked to participate in the second (self-monitoring) phase of the study. Subjects were selected to generate a sample stratified for age (less than $30,31-44,45$ or over), sex, and diagnostic group. All participants were paid for their participation in this phase of the experiment.

\section{Unpleasant Events Schedule: Form II}

On the basis of item analyses, some items with very low frequency or aversiveness ratings were eliminated. In addition, a few grammatical changes were made, and a few items which had been repeated were identified. A total of 17 new items from the item pool were added. The 320 items were thoroughly randomized to constitute UES, Form II. The Phase II participants took the UES at the beginning and at the end of the 30-day monitoring period.

\section{Other Measures}

Daily self-monitoring and events lists. An individualized list, consisting of 160 events judged by the participant to be most aversive on the Ünpleasant Events Schedule, was constructed for each participant. The participants were asked to rate each item on their list on a 3point scale from 0 to 2 at the end of each day indicating whether the event had not occurred $(0)$, had occurred and was experienced as neutral (1), or had occurred and was experienced as unpleasant (2).

Daily mood ratings. The participants were also asked to fill out alternate forms of the Depression Adjective Check Lists (Lubin, 1965) at the end of each day. A total mood score based on the number of dysphoric mood adjectives checked plus the number of positive adjectives not checked was computed for each day. (A high score is indicative of negative mood.) Each completed daily set (mood rating and events list) was returned by mail by the subjects for 30 consecutive days.

Beck Depression Inventory. Since most of the depressed patients were no longer depressed at the beginning of Phase II, no differences between diagnostic groups were expected. In order to assess each participant's depression level, the Beck Depression Inventory (Beck, 1961) was administered at the beginning, in the middle, and at the end of the 30-day self-monitoring period. On the basis of their first Beck Depression Inventory score, the participants were trichotomized into "least" (range 0-3, mean $=1.7$, $N=21$ ), "intermediate" (range 4-10, mean = $6.7, N=18$ ), and "most" (range 11-32, mean = 
15.6, $N=19$ ) depressed subgroups. In addition, by inspecting each participant's Beck score at the beginning, middle, and end of the 30-day period, the experimenters, working together, categorized the participants into those whose scores decreased and who presumably had become less depressed over the period, those whose scores showed little change, and those whose scores increased. The mean Beck scores for the three groups are shown in Table 2.

\section{RESULTS}

\section{Psychometric Properties of the Unpleasant Events Schedule}

\section{Test-Retest Stability}

Test-retest reliability coefficients for intervals of one, two, and three months were computed for each of the three diagnostic groups and for the total satpple. The latter are shown in Table 3. As can bd seen, individual reliability coefficients ranged from .02 to .73 , with a mean of .51 . Test-retest reliability was lowest for the frequency ratings on Scales 01, 05, and 07. Since these scales (especially Scales 05 and 07) deal with very infrequently occurring events, their test-retest reliability was expected to be lower.

A comparison of the three diagnostic groups indicated that the test-retest reliability was highest for the depressives (mean reliability $=.61$ ) and for the high-MMPI controls (mean reliability $=.57$ ), and lowest for the normal controls (mean reliability $=.39$ ). Test-retest reliability coefficients for UES, Form II, for a one-month interval are also shown in Table 3.

\section{Internal Consistency}

A measure of intra-scale homogeneity derived from domain sampling theory is coefficient alpha (Cronbach, 1951). This coefficient may be interpreted as the expected correlation of a given scale with any other alternative scale composed of similar items of equal length. The alpha coefficients for the scales are shown in Table 3. As can be seen, the scales possess high intra-scale consistency as measured by coefficient alpha.

\section{Predictive and Concurrent Validity}

\section{Correlation with Daily Monitoring Data}

The Phase II participants $(N=58)$ had filled out the UES at the beginning (T1) and at the end (T2) of the 30-day daily monitoring period. Since the T2 UES frequency ratings covered the same period of time as the daily monitoring data, the correlation between them represents a measure of the accuracy with which the subjects reported on the frequency of occurrence of the events. The correlation between the T2 UES frequency ratings (Scale $00-$ All items) and the mean number of events which the subjects reported as occurring during the 30 -day monitoring period was $.63(p<.001)$.

\section{Table 2}

Mean Beck Depression Inventory Scores for Phase II Participants at Beginning, Middle and End of the 30 Day Self-Monitoring Period

\begin{tabular}{llrrr}
\hline \hline Group & N & Beginning & Middle & End \\
\hline 1. "less depressed" & 12 & 13.3 & 6.7 & 6.3 \\
2. "no change" & 30 & 6.7 & 6.6 & 7.0 \\
3. "more depressed" & 17 & 6.3 & 12.5 & 11.5 \\
Total & 58 & 7.8 & 8.7 & 8.2 \\
\hline
\end{tabular}


Table 3

Test-Retest Stability and Coefficient Alpha for the UES Scales

\begin{tabular}{|c|c|c|c|c|c|c|}
\hline Scale & & $\begin{array}{l}\text { UES } \\
1 \mathrm{mo} . \\
\end{array}$ & $\begin{array}{l}\text { I } \quad(N=8 \\
r \quad \\
2 \text { mo. }\end{array}$ & 38) & $\begin{array}{c}\text { Coefficient } \\
\text { alpha }\end{array}$ & $\begin{array}{c}\text { UES II } \\
\begin{array}{c}(\mathrm{N}=58) \\
\mathrm{r}\end{array} \\
1 \mathrm{mo} .\end{array}$ \\
\hline $00 \begin{array}{l}\mathrm{A} 11 \\
\text { Items }\end{array}$ & $\begin{array}{l}\text { Freq. } \\
\text { Aver. } \\
\text { Cross }\end{array}$ & $\begin{array}{l}.67 \\
.67 \\
.62 \\
\end{array}$ & $\begin{array}{l}.68 \\
.61 \\
.64 \\
\end{array}$ & $\begin{array}{l}.64 \\
.45 \\
.52 \\
\end{array}$ & $\begin{array}{l}.96 \\
.98 \\
.96 \\
\end{array}$ & $\begin{array}{l}.63 \\
.82 \\
.78 \\
\end{array}$ \\
\hline 01 Health & $\begin{array}{l}\text { Freq. } \\
\text { Aver. } \\
\text { Cross }\end{array}$ & $\begin{array}{l}.30 \\
.58 \\
.29 \\
\end{array}$ & $\begin{array}{l}.29 \\
.63 \\
.34 \\
\end{array}$ & $\begin{array}{r}.23 \\
.46 \\
.23 \\
\end{array}$ & $\begin{array}{l}.76 \\
.94 \\
.76 \\
\end{array}$ & $\begin{array}{l}.61 \\
.75 \\
.63 \\
\end{array}$ \\
\hline $\begin{array}{l}02 \text { Achiev., } \\
\text { Academic, } \\
\text { Job } \\
\end{array}$ & $\begin{array}{l}\text { Freq. } \\
\text { Aver. } \\
\text { Cross }\end{array}$ & $\begin{array}{l}.63 \\
.66 \\
.54 \\
\end{array}$ & $\begin{array}{l}.67 \\
.60 \\
.66 \\
\end{array}$ & $\begin{array}{l}.72 \\
.44 \\
.54 \\
\end{array}$ & $\begin{array}{l}.81 \\
.87 \\
.79 \\
\end{array}$ & $\begin{array}{l}.57 \\
.75 \\
.57 \\
\end{array}$ \\
\hline $\begin{array}{r}04 \text { Sexual, } \\
\text { Marital }\end{array}$ & $\begin{array}{l}\text { Freq. } \\
\text { Aver. } \\
\text { Cross } \\
\text { Freq. } \\
\text { Aver. } \\
\text { Cross }\end{array}$ & $\begin{array}{l}.73 \\
.66 \\
.63 \\
.63 \\
.70 \\
.62 \\
\end{array}$ & $\begin{array}{l}.58 \\
.60 \\
.57 \\
.62 \\
.61 \\
.57 \\
\end{array}$ & $\begin{array}{l}.59 \\
.46 \\
.47 \\
.62 \\
.42 \\
.54 \\
\end{array}$ & $\begin{array}{l}.74 \\
.86 \\
.76 \\
.67 \\
.81 \\
.69 \\
\end{array}$ & $\begin{array}{l}.62 \\
.81 \\
.67 \\
.64 \\
.76 \\
.72 \\
\end{array}$ \\
\hline 05 Legal & $\begin{array}{l}\text { Freq. } \\
\text { Aver. } \\
\text { Cross }\end{array}$ & $\begin{array}{l}.33 \\
.59 \\
.05 \\
\end{array}$ & $\begin{array}{l}.18 \\
.47 \\
.17 \\
\end{array}$ & $\begin{array}{l}.03 \\
.49 \\
.02 \\
\end{array}$ & $\begin{array}{r}.70 \\
.89 \\
.71 \\
\end{array}$ & $\begin{array}{l}.23 \\
.64 \\
.16 \\
\end{array}$ \\
\hline $\begin{array}{c}06 \text { Material, } \\
\text { Financial }\end{array}$ & $\begin{array}{l}\text { Freq. } \\
\text { Aver. } \\
\text { Cross }\end{array}$ & $\begin{array}{l}.62 \\
.61 \\
.69 \\
\end{array}$ & $\begin{array}{l}.53 \\
.55 \\
.56 \\
\end{array}$ & $\begin{array}{l}.50 \\
.50 \\
.55 \\
\end{array}$ & $\begin{array}{r}.70 \\
.90 \\
.78 \\
\end{array}$ & $\begin{array}{l}.51 \\
.69 \\
.50 \\
\end{array}$ \\
\hline $\begin{array}{l}07 \text { Social } \\
\text { Exits }\end{array}$ & $\begin{array}{l}\text { Freq. } \\
\text { Aver. } \\
\text { Cross }\end{array}$ & $\begin{array}{l}.28 \\
.67 \\
.43 \\
\end{array}$ & $\begin{array}{l}.27 \\
.60 \\
.29 \\
\end{array}$ & $\begin{array}{r}.22 \\
.40 \\
.32 \\
\end{array}$ & $\begin{array}{l}.60 \\
.87 \\
.61 \\
\end{array}$ & $\begin{array}{l}.54 \\
.67 \\
.54 \\
\end{array}$ \\
\hline $\begin{array}{l}08 \text { Most } \\
\text { Discrim. } \\
\text { Items } \\
\end{array}$ & $\begin{array}{l}\text { Freq. } \\
\text { Aver. } \\
\text { Cross }\end{array}$ & $\begin{array}{l}.70 \\
.62 \\
.68 \\
\end{array}$ & $\begin{array}{l}.66 \\
.57 \\
.64 \\
\end{array}$ & $\begin{array}{l}.60 \\
.40 \\
.53 \\
\end{array}$ & $\begin{array}{l}.82 \\
.88 \\
.88 \\
\end{array}$ & $\begin{array}{l}.64 \\
.84 \\
.73 \\
\end{array}$ \\
\hline
\end{tabular}


The correlation between the UES T1 frequency ratings and the daily monitoring totals (for Phase II participants) could be used as a measure of the predictive validity of the UES frequency ratings. The correlation was $.44(p<$ $.001)$, indicating that the self-reported daily occurrence of aversive events can be predicted to some extent from the person's UES frequency ratings for the preceding month.

\section{Correlation with Social \\ Readjustment Rating Scale}

The concurrent validity of the UES scores could also be examined from the Phase I data on the basis of the magnitude of the correlations between selected UES scores (all items and Social Exits Scale) and the Social Readjustment Rating Scale values. These correlation coefficients ${ }^{2}$ were small (mean $=.10$; range .03 to .21 ), accounting for a very small proportion of the variance. The lack of relationship between the UES and the SRRS measures was not unexpected. Most of the SRRS items refer to very infrequently occurring events; and inspection of the Life Change Unit scores indicated that their distribution was extremely skewed, with most of the subjects attaining zero or very low scores on the SRRS.

\section{Intercorrelations Between UES Scales and the Frequency and Aversiveness Ratings}

The first question of interest was the degree to which the UES scales were correlated with each other. Correlation coefficients between all scales were computed ${ }^{2}$. For the frequency ratings, mean correlation across scales was . 42 (range .21 to .59). For the aversiveness ratings, the mean correlation across scales was .68 (range .49 to .83). While the magnitude of the interscale correlations was lower than the test-retest reliability coefficients, in all instances the interscale correlations were statistically significant at less than the .05 level; and the "rational" scales developed should be viewed as a first step toward scale construction. Inspection of the total interscale correlation matrix also revealed the very high degree of association between the Most Discriminating Item scale and scores based on the total item set, Scale 00 ( $r$ for frequency ratings $=.81$; for aversiveness ratings $=.91$; and for the cross-product score $=.89$ ), suggesting that Scale 08 , which has only 27 items, may be useful as a short form with little loss of internal consistency if the occurrence of specific events is not of concern.

A second question of interest was the degree of correlation between the frequency and the aversiveness ratings for each scale. This is especially germane to the rationale for eliciting separate frequency and aversiveness ratings to the events; i.e., it was assumed that the frequency and aversiveness ratings represent separate and, hopefully, orthogonal dimensions of individual difference. The correlations ${ }^{2}$ between the frequency and the aversiveness ratings were computed for all scales. The magnitude of these correlations tended to be low and typically positive (mean $r=.14$; range -.06 to .33 ), indicating either the existence of a response set or of a small but consistent tendency on the part of individuals who have a higher number of events to also experience them as slightly more aversive.

Finally, it was of interest to ascertain the relationship between the mean frequency of occurrence and the mean rated aversiveness of the events. This correlation ${ }^{2}$ was $-.49(p<.001)$. As might be expected, the most aversive events (e.g., being physically threatened) occurred within the lowest frequencies.

\section{Relationship with Age}

The sample was dichotomized at the median (25) into younger $(N=110)$ and older $(N=101)$ subgroups. Mean scale scores for younger and older participants were compared by analysis of covariance with sex as the covariate. ${ }^{2}$ There was a slight tendency for the younger subjects to report a higher rate of occurrence of aversive events which attained statistical significance for 
Scales 00,02 , and 04 . None of the differences on the aversiveness ratings attained statistical significance. The relative absence of differences between age groups should be interpreted cautiously, since the age range of the present sample was relatively restricted and included few subjects over the age of 60 .

\section{Relationship with Sex}

Mean scores $^{2}$ for male and female subjects, averaged across diagnostic groups, were also computed. Differences were compared by analysis of covariance with age as the covariate. Males attained a slightly higher frequency mean on Scale 06. There also was a small but consistent tendency on the part of the female participants to rate the events as slightly more aversive. These differences attained statistical significance on Scales 00, 01, 06, and 07.

\section{Relationships with Depression}

Differences between depressed and non-depressed on the UES variables. Means for the diagnostic groups on the UES scales were computed. ${ }^{2}$ Since the groups were not matched for age and sex, the data were analyzed by analysis of covariance with age and sex as covariates. Differences between groups on the frequency ratings were small and attained statistical sig nificance only for Scales $00,01,06$, and 08 , with the depressives and the high-MMPI controls attaining slightly higher scores than the normal controls. Since the items for Scale 08 had been selected because they were found to discriminate between the depressed and the non-depressed groups, differences between groups on this scale should be treated very cautiously pending independent cross-validation. By contrast, differences between groups on the aversiveness ratings were larger and statistically significant except for Scales 01, 05, and 07. The depressed consistently rated the events as more aversive than the two control groups. On the crossproducts scores, the depressed attained sub- stantially higher scores than either of the control groups on all scales except for Scales 05, 06, and 07.

Since many of the depressed were no longer depressed during Phase II, the relation between depression level and the UES scores was evaluated by computing the correlation between the subject's Beck Depression Inventory Score (taken at beginning of the 30-day monitoring period) and the mean frequency, aversiveness, and cross-products scores for Scale 00 (all items). The corresponding correlation coefficients were .13 (N.S.), $.26(p<.05)$, and .34 ( $p<$ .01).

Dimensional analysis of "Most Discriminating" (MD) items. As will be recalled, each of these 27 items had been found to be highly discriminating between depressed and non-depressed subjects. Their factorial structure was of interest, with the expectation that the dimensions so identified might clarify the nature of events associated with depression. The frequency, aversiveness, and cross-products scores for the MD items, for all subjects $(N=202)$, were separately submitted to principal components factor analysis. Six factors (which accounted for $49 \%, 51 \%$, and $46 \%$ of the total variance for the frequency, aversiveness, and cross-products scores, respectively) were extracted and rotated to simple structure according to the varimax criterion. Since the correlations between the frequency and aversiveness means for items had been found to be negative, the factorial structure of the three matrices was expected and was found to be somewhat different. Nevertheless, by identifying items which loaded on what appeared to be similar factors across the three matrices and by examining the intercorrelations between these items within each matrix, it was possible to generate the five clusters which are shown in Table 4. The clusters were tentatively labeled as Social Isolation, Marital Discord, Inconveniences, Work Hassle, and Negative Social Interaction.

Differences between more and less depressed subjects on the daily monitoring data. A further 
Table 4

Clusters Identified from Factor Analyses of Frequency, Aversiveness and Cross-Product Scores for the Most Discriminating Items (K=27)

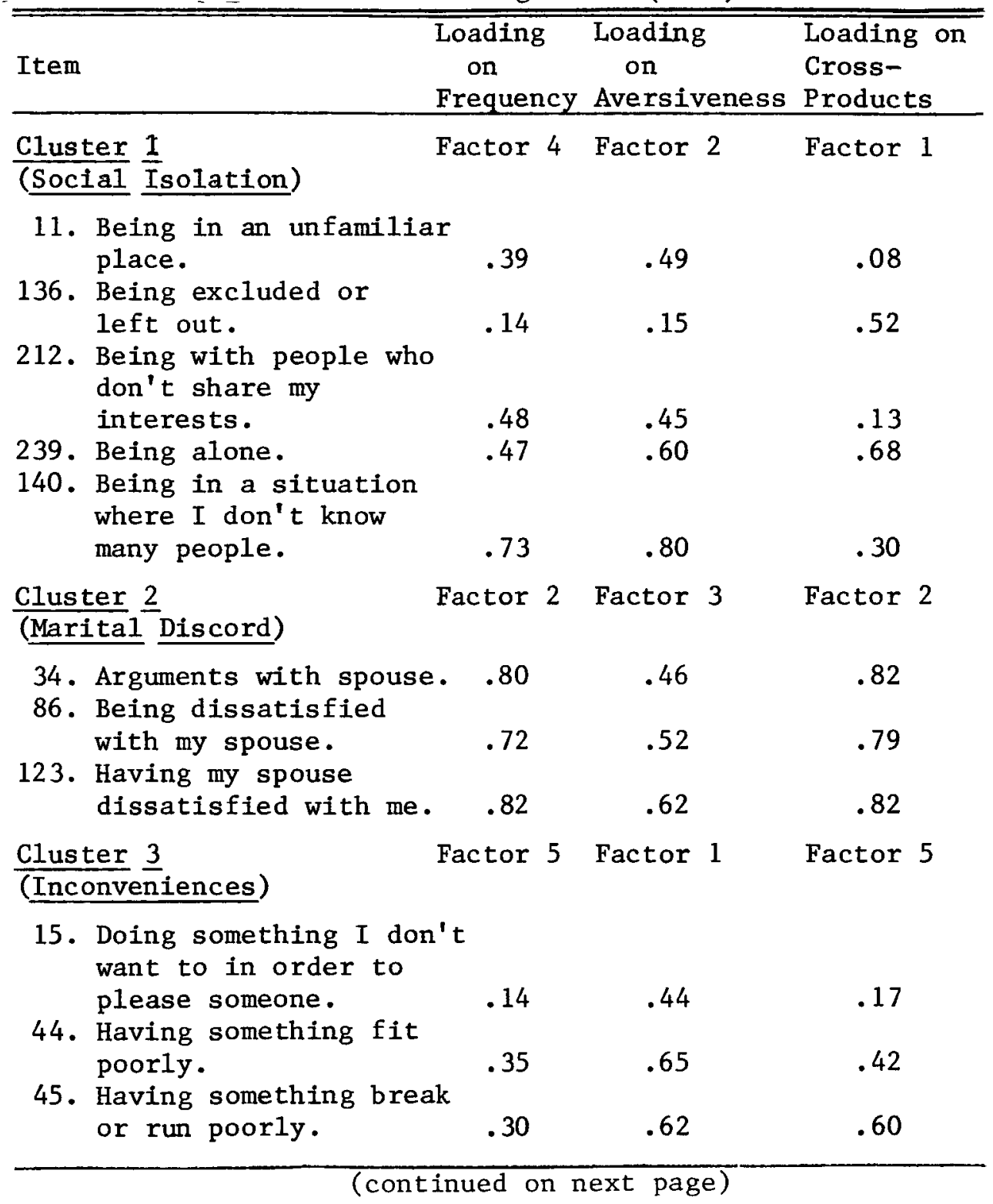


Table 4, continued

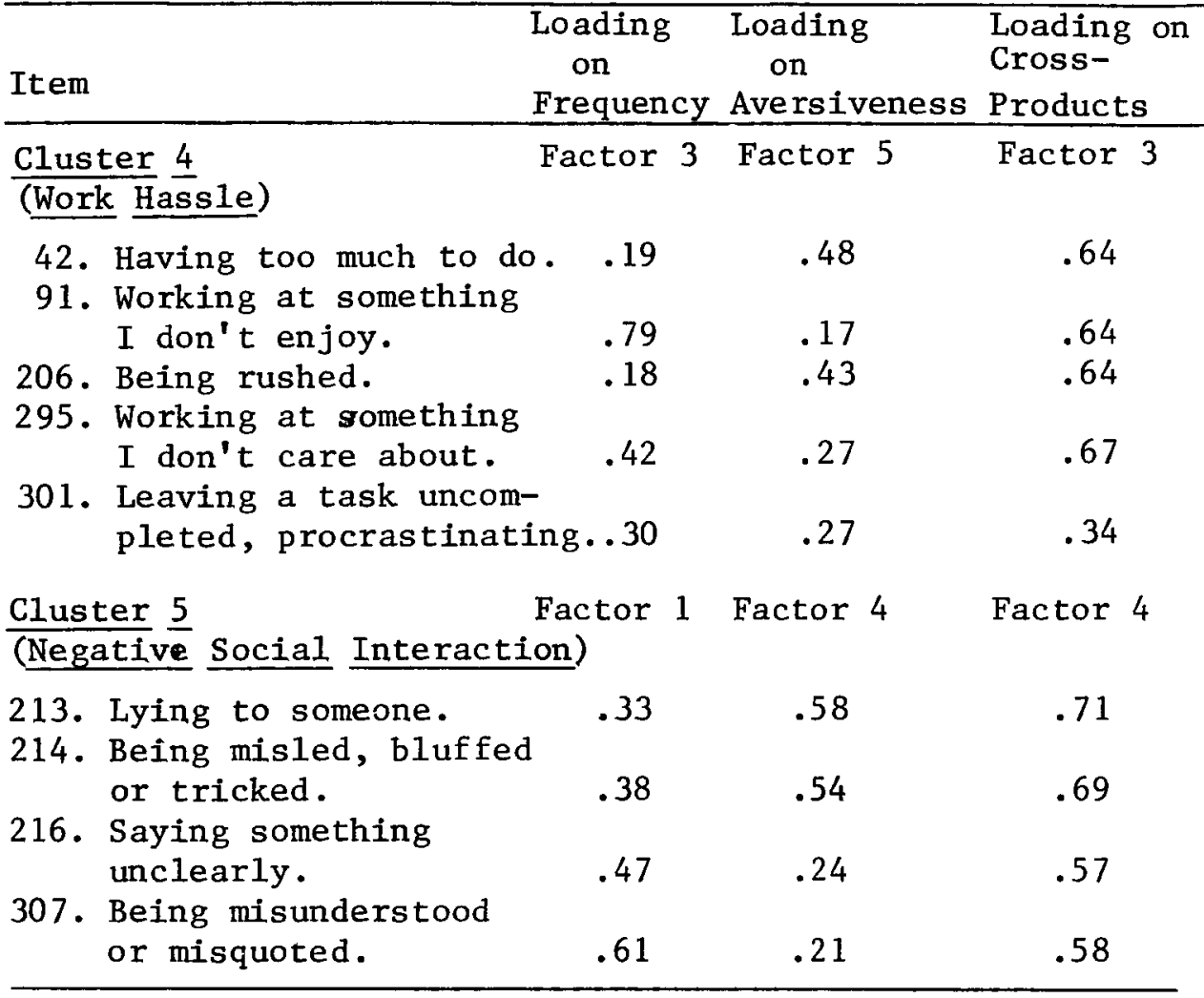

test of the association between depression level and the occurrence of aversive events could be made on the daily monitoring data of the Phase II participants. The latter, who had been trichotomized into "most," "intermediate," and "least" depressed subgroups on the basis of their scores on the Beck Depression Inventory, had rated the daily occurrence of 160 events on a 3 -point scale with $0=$ the event had not occurred, $1=$ the event had occurred but was not experienced as aversive, and $2=$ the event had occurred and was experienced as aversive. From these daily monitoring data, two scores were computed: Score 1, a daily total unpleasant events score obtained by summing the number of events which had occurred (rating $\neq 0$ ); and Score 2, a daily total unpleasant events score obtained by summing the number of activities which had occurred and were also rated as unpleasant (rating $=2$ ). To examine the data for the existence of systematic time trends, separate daily monitoring means were computed for Days $1-10,11-20$, and 21-30. The results were analyzed by means of a repeated-measurements analysis of covariance separately for Scores 1 and 2 with age and sex as covariates. ${ }^{2}$

For both averaged daily aversive events scores, there were cignificant main effects due to groups $(F=3.0, \mathrm{p}<.06$ for Score 1 , and $F=4.6, p<$ .01 for Score 2), with the most depressed attaining higher scores than the intermediates, who in turn had higher scores than the least depressed (23.8, 18.0, 15.5 for Score 1 and 17.3, 10.2, and 8.8 for Score 2). The strength of the association is reflected by the magnitude of the correlation between the Beck Depression Inventory scores 
and Scores 1 and 2 (across all subjects) which were $.26(p<.05)$ and $.39(p<.01)$, respectively.

There was also a significant tendency for all subjects to report fewer aversive events across the three successive 10-day monitoring periods. For Score 1, the means were 21.6, 18.2, and $17.4 ; F=21.0, p<.000$. For Score 2 , the means were 13.6, 11.8, and $10.9 ; F=5.1, p<.007$. Since the likelihood that there was an objective decrease in the occurrence of aversive events in the subjects' lives during this particular time period is very remote, the existence of a systematic response set for people to report (notice?, remember?) fewer aversive events over a period of extended self-monitoring was hypothesized. Since the interaction between depression level groups by time periods was not statistically significant for either Score 1 or Score $2(F<1.0$ for either score), it may be inferred that this tendency to report fewer aversive events over time was shown equally by the three depression level groups. A similar time trend was not found when subjects (non-depressed and depressed not in treatment) self-monitored the occurrence of pleasant events over 30 days using procedures analagous to those used in the present investigation (Lewinsohn \& Graf, 1973).

Association between daily occurence of aversive events and fluctuations in daily mood. Two questions were of interest: Is there a significant association between the daily rate of occurrence of aversive events and mood? If so, does the degree of association vary systematically as a function of age, sex, or history of depression? The Phase II participants, it will be recalled, had been selected to generate a sample stratified for sex, age ( 30 or less, $31-44,45$ or over), and diagnostic categorization (Depressed, High-MMPI Control, Normal Control). They had monitored their daily mood and the daily occurrence of 160 events for 30 days. The correlation between the mood scores (a high score is indicative of negative mood) and the daily aversive events scores across the $\mathbf{3 0}$ days was computed separately for each subject. The means of these correlations (which had been transformed to $Z$ scores) were compared across groups by means of ANOVA. The mean of the correlations between mood and the daily aversive events for all subjects was statistically significant $(r=.29, t$ $=7.25, p<.001)$; and the null hypothesis $(r=0)$ was strongly rejected. Neither the main effects due to age, sex, diagnostic group, or their interactions attained statistical significance.

Changes associated with improvement in depression level: UES scales. The following questions were of interest: Is improvement in clinical depression accompanied by a decrease in the reported rate of occurrence and experienced aversiveness of unpleasant events as reflected by the UES scores? If so, is the decrease greater in more improved than in less improved depressives? Affirmative answers to both of these questions would strengthen the functional relationship between depression and the events measured by the UES. Negative findings (i.e., continued elevation of depressives on UES scales on which they were found to be elevated prior to treatment even after recovery) would suggest that the variables being measured by the UES constitute relatively stable characteristics of depressives.

In interpreting these findings, the following considerations are relevant:

1. All participants took the UES at four monthly intervals,

2. The depressed as a group improved substantially from T1 (intake) to T4 (Zeiss, Lewinsohn, \& Munoz, 1978).

3. The more improved group changed more than the less improved group, but their initial depression level was comparable.

4. All depressed patients were provided with treatment which had a duration of four weeks.

5. Patients were randomly assigned to an immediate treatment (started at T1) and to a delayed treatment (started at T2) condition.

Thus, T4 was a 2-month post-treatment for half of the depressives and a 1 -month post-treatment for the other half. 
The data were analyzed sequentially by means of repeated-measurements analysis of covariance with age and sex as covariates. A first concern was whether there were significant differences between the high-MMPI control and the normal controls and whether there were significant changes over time in the UES ratings of the two non-depressed groups; hence, a subanalysis of the data for the high-MMPI and normal controls was done. The results indicated that none of the differences between these two groups attained statistical significance (hence, in subsequent analyses they were combined into a single non-depressed control group); and there was a significant decrease in the frequency ratings by the non-depressed controls on Scale 00 $(F=6.1, p<.001)$; Scale $03(F=6.1, p<.001)$; Scale $04(F=3.8, p<.01)$; Scale $06(F=3.3, p<$ $.02)$; Scale $07(F=3.7, p<.01)$; and Scale $08(F$ $=4.9, p<.003$ ). Inspection of the data indicated that the drop occurred between $\mathrm{T} 1$ and $\mathrm{T} 2$. The results thus suggest the presence of a response set to report fewer aversive events, as a function of repeated self-reporting, similar to the one which was hypothesized to account for the frequency drop observed with daily monitoring data. In contrast to the frequency ratings, changes on the aversiveness ratings across the time periods were small and in no instance attained statistical significance.

In the second subanalysis, change on the UES scales across the time periods by the depressed was compared with the combined non-depressed control group. The general hypothesis was that change (a decrease) for the depressed would be greater than for the controls; hence, it was expected that the interaction of groups by time periods would be statistically significant. The results were as follows:

1. Contrary to prediction, the interaction was not statistically significant for the frequency ratings except for Scale $08(F=5.6, p<$ $.001)$.

2. As predicted, the interaction for the aversiveness ratings was significant for Scales 00

$$
\begin{aligned}
& (F=5.5, p<.001) ; 02(F=6.9, p<.000) ; 03 \\
& (F=5.7, p<.001) ; 04(F=6.6, p<.000) ; 07 \\
& (F=2.7, p<.04) ; \text { and } 08(F=7.5, p<.000) .
\end{aligned}
$$

3. As predicted, the interaction for the crossproducts scores was signifcant for Scales 00 $(F=7.4, p<.000) ; 01(F=2.6, p<.05) ; 02$ $(F=5.2, p<.002) ; 03(F=4.9, p<.002)$; and $08(F=15.3, p<.000)$.

An indication of the degree to which the depressed had changed on the UES scores from T1 to $\mathrm{T} 4$ is provided by the fact that at $\mathrm{T} 4$ all but one of the differences between the depressed and non-depressed failed to attain statistical significance. For the frequency ratings on Scale 02 , the depressed at T4 had a lower mean (.42 vs. $.52)$ than the controls $(F=3.9, p<.05)$.

The final subanalysis involved a comparison of change on the UES scales across the time periods between the more and less improved depressives. While there was a general tendency for the more improved to change more than the less improved, none of the interactions for the frequency and aversiveness ratings attained statistical significance. However, for the crossproducts scores, the interaction was significant for Scale $00(F=2.5, p<.06)$, Scale $03(F=3.8$, $p<.01)$, and Scale $08(F=2.6, p<.05)$, with the more improved showing a greater decrease than the less improved.

Changes associated with improvement in depression level: daily monitoring data. The daily monitoring data provided another opportunity to test the hypothesis that changes in depression level would be associated with parallel change in the reported occurrence of aversive events. It will be recalled that the Phase II participants had been trichotomized into those whose Beck Depression Inventory (BDI) scores decreased over the 30-day period ("less depressed" group), those whose BDI remained unchanged ("no change" group), and those whose BDI scores increased ("more depressed" group). Mean BDI scores for the groups are provided in Table 2. Differences between groups were tested by repeated-measurements analysis of co- 
variance with age and sex as covariates. While the results were in the predicted direction (i.e., the mean number of events which occurred and were reported as unpleasant dropped more for the less depressed group [ 15.3 on Days $1-10$ to 8.7 on Days 21-30] than for the more depressed group [16.8 to 13.7$]$ and remained relatively stable for the "no change" group [10.9 to 9.6]), the critical interaction of groups by time periods failed to attain statistical significance $(F=1.7, p$ $<.16)$.

Relationship between depression and the Social Readjustment Rating Scale. Mean Life Change Unit (LCU) scores and a weighted Social Exits score (based on the following subset of the SRRS items: death of spouse, death of close family member, death of a close friend, son or daughter leaving home, marital separation, divorce) were computed for the three diagnostic groups. The results, shown in Table 5, replicate those of Paykel et al. (1969) in showing events involving "social exits" to be uniquely elevated in depressives during the six-month period preceding intake.
Relationships of the UES and the SRRS variables with endogeneity and reactivity. The depressives had been categorized on the basis of their symptoms into high-high, high-low, lowhigh, and low-low subgroups on "endogeneity" and "reactivity" dimensions identified in an earlier investigation (Lewinsohn et al., 1977). The data were analysed by a two-factor analysis of covariance with age and sex as covariates. ${ }^{2}$ The general hypothesis that depressives high on the reactivity factor would be higher on the stress measures was not supported. These negative results are consistent with those obtained by Leff, Roatch and Bunney (1970) and by Thompson and Hendrie (1972).

\section{DISCUSSION}

The major objective of this investigation was to develop a psychometrically sound instrument for the measurement of aversive events. An initial version of the UES was developed and tested on 202 subjects. On the basis of item analyses, the instrument was revised and tested

Table 5

Mean Social Readjustment Rating Scale Scores

(Total Life Change Units and Social Exits)

for the diagnostic groups.

\begin{tabular}{|c|c|c|c|c|}
\hline \multirow[b]{2}{*}{ Group } & \multicolumn{2}{|c|}{$\begin{array}{l}\text { Total Life } \\
\text { Change Units }\end{array}$} & \multicolumn{2}{|c|}{ Social Exits } \\
\hline & $\overline{\mathrm{X}}$ & $\sigma$ & $\overline{\mathrm{x}}$ & $\sigma$ \\
\hline $\begin{array}{l}\text { Depressed } \\
N=75\end{array}$ & 181.9 & 132.7 & 20.4 & 37.0 \\
\hline $\begin{array}{l}\text { High-MMPI } \\
\text { Controls } \\
\mathrm{N}=66\end{array}$ & 140.6 & 88.2 & 6.4 & 19.2 \\
\hline $\begin{array}{l}\text { No rmal } \\
\text { C ontrols } \\
N=78\end{array}$ & 121.4 & 84.4 & $4: 6$ & 15.5 \\
\hline $\begin{array}{l}\mathrm{F} \\
\mathrm{p}\end{array}$ & & $\begin{array}{l}6.6 \\
.002\end{array}$ & & \\
\hline
\end{tabular}


on a subset of the 202. Support for the accuracy with which people report on the frequency of occurrence of the events during the preceding month was provided by the magnitude of the correlations found for the Phase II participants between the UES scores and the daily monitoring data covering the same time period. The fact that the test-retest stability (at monthly intervals) was also reasonably high suggests that many of the events being measured by the UES represent ongoing sources of experienced aversiveness. Individuals who scored high on the frequency ratings at the initial UES administration also tended to report a larger number of aversive events in their daily monitoring during the next month and on subsequent monthly readministrations of the UES. The high test-retest stability of the aversiveness ratings suggests that the degree of aversiveness with which events are experienced is a stable characteristic of people (i.e., individuals differ systematically in the types of events they experience as aversive, and such differences remain relatively stable over time). The common practice of assigning constant weights to events appears unjustified.

One of the distinguishing characteristics of the UES is that it calls for separate ratings of the frequency and of the aversiveness of the events. The generally low intercorrelations between individual's frequency and aversiveness ratings indicates that the frequency with which events occur and the aversiveness with which they are experienced are indeed separate variables. The unexpected, relatively small but consistent drop in the frequency ratings which occurred between the first and the second monthly ratings represents a potential confounding factor for longitudinal studies concerned with the evaluation of systematic changes in experienced aversiveness over time.

On the basis of the data collected in this study, 33 additional items from UES, Form II, were eliminated with the following criteria: (1) items with very low aversiveness ratings; (2) one of any pair of items whose frequency and aversiveness ratings were highly intercorrelated, and were therefore presumed to be redundant; and (3) items whose test-retest reliability (one month) on the aversiveness ratings was low $(r<.3)$. These items were replaced with new items generated by 36 adolescents (ages 12 to 18 ) and 38 elderly persons (over age 60). Normative data on a large community sample, stratified by age and sex, are currently being collected for UES, Form III.

The correlations between the UES and the SRRS scores were positive, but very low, and accounted for very little variance. Clearly, the two instruments are not measuring the same variable(s). Part of this lack of correlation may be at tributable to the different time frames (preceding six months vs. preceding one month). However, using an SRRS score based only on events which occurred during the preceding month did not substantially increase the magnitude of the correlations. Another possible reason for the failure of the two measures of stressful experience to correlate with each other may be represented by the very low rate of occurrence of the SRRS items, resulting in a very skewed and restricted distribution of scores.

Perhaps more fundamentally relevant to any comparison between the UES and SRRS, and to future studies on the relationship between stressful life experiences and disorder, is the conceptual distinction made by Ilfeld (1976a, 1976b, 1977) between past events which are fortuitous and time-limited (e.g., the accidental, sudden death of a close relative; house destroyed by flood or fire) and what Ilfeld calls "current social stressors that are patterned into our everyday roles as marital partners, breadwinners, and parents ...." (Ilfeld, 1977, p. 162), e.g., arguments with spouse, having too much to do. While neither the SRRS nor the UES are completely restricted to only one of these two types of events, their relative representation clearly differs, with the SRRS having a larger number of discrete, one-time events (e.g., marriage, death of spouse, divorce), while the UES has a larger proportion of events which represent ongoing sources of distress. There is no reason why these 
two types of events should be correlated with each other. Nevertheless, methodologically, conceptually, and clinically, it is likely to be useful to distinguish between them.

Support for the validity of the UES was provided largely in the form of construct validity, i.e., relationships with depression were investigated. There were strong theoretical and empirical grounds for expecting such relationships. Thus, the potential importance of "losses" of various sorts for depression has been recognized (e.g., Freud, 1917/1957; Harlow, 1962); and a subgroup of "reactive" depressives has been postulated by many to encompass those patients whose depression onset follows the occurrence of stressful life events (Gillespie, 1929). The hypothesis that depressives are more sensititive to aversive events has also been tested and supported in several previous studies (Lewinsohn, Lobitz, \& Wilson, 1973; Libet, Lewinsohn \& Javorek, 1973; Stewart, 1968). Similarly, Schless, Schwartz, Goetz, \& Mendels (1974) found depressives to rate stressful life events as more aversive than a control group.

The UES frequency data can be summarized by stating that the depressed were neither markedly, nor uniquely, elevated in the overall frequency with which they reported aversive events during the 30-day period preceding intake. Both the high-MMPI controls and the depressed attained slightly higher frequency scores than the normal controls; but on most comparisons, the high-MMPI controls attained the highest scores. On the other hand, the depressives did attain the highest frequency scores on the post-hoc Most Discriminating Item Scale. This finding needs to be treated cautiously pending cross-validation. However, the types of events on the MD scale, as clarified by the factor (cluster) analysis, showed considerable resemblance to the types of "social stressors" found to be most highly correlated with depression by IIfeld; 1977). Ilfeld found marital stressors to have the highest correlation with depression symptoms $(r \approx .4)$ followed by lower, but statistically significant, relationships with "stressors" in the areas of parenting, job, and finances.

On the aversiveness ratings, the depressed were uniquely elevated on all scales except Scales 01 (Health and Welfare), 05 (Legal), 06 (Material, Financial), and 07 (Social Exits). The results thus provide partial confirmation of the findings of Schless et al. (1974) in showing depressives to rate some, but not all, events as more aversive. The fact that depressed were not particularly elevated in their aversiveness ratings of the events on Scales 01, 05, 06, and 07, which include many of the most aversive events, argues against the presence of a general response set on the part of depressives to rate all events as more aversive. Rather, the results suggest that certain kinds of events (i.e., those pertaining to academic-achievement-job, domestic inconveniences, and sex-marital-friendship) are experienced as especially aversive by depressed patients.

The UES scales were found to be sensitive to clinical improvement in depression level; and at the final post-treatment assessment, the depressives were indistinguishable from the controls. The daily monitoring data also supported the relationship between depression level at the beginning of the observation period and the total number of aversive events reported for the subsequent 30-day period. Likewise, a significant association was found between the daily rate of occurrence of aversive events and daily mood.

\section{References}

Beck, A. T. An inventory for measuring depression. Archives of General Psychiatry, 1961, 4, 561-571.

Cronbach, L. Coefficient alpha and the internal structure of tests. Psychometrika, 1951, 16, 297-334.

Dekker, D., \& Webb, J. Relationships of the social readjustment rating scale to psychiatric status, anxiety, and social desirability. Journal of Psychosomatic Research, 1974, 18, 125-130.

Dohrenwend, B. S., \& Dohrenwend, B. D. (Eds.), Stressful life events: Their nature and effects. New York: John Wiley \& Sons, 1974. 
Freud, S. Mourning and melancholia. In The Complete Works of Sigmund Freud (Vol. 14). London: Hogarth Press, 1957, 243-258. (Originally Published, 1917.)

Gersten, J., Langner, T., Ersenberg, L., \& Orzek, L. In B. S. Dohrenwend \& B. P. Dohrenwend (Eds.), Stressful life events: Their nature and effects. New York: John Wiley \& Sons, 1974.

Gillespie, R. D. The clinical differentiation of types of depression. Guy's Hospital Reports, 1929, 79, 306-304.

Grinker, R. R., Miller, J., Sabshin, M., Nunn, R., \& Nunally, J. D. The phenomena of depressions. New York: Paul B. Hoeber, Inc., 1961.

Gunderson, E. K., E., \& Rahe, R. H. Life stress and illness. Springfield, IL: Charles C. Thomas, 1974.

Harlow, H. F. The heterosexual affectional system in monkeys. American Psychology, 1962, 17.1-9.

Hawkins, N. G., Davies, R., \& Holmes, T. H. Evidence of psychosocial factors in the development of pulmonary tuberculosis. American Review of Tuberculosis and Pulmonary Disease, 1957, 75, 768-780.

Holmes, T. H., \& Rahe, R. H. The social readjustment rating scale. Journal of Psychosomatic Research, 1967, 11, 213-218.

Hudgens, R. W., Morrison, J. R., \& Barchha, R. G. Life events and onset of primary affective disorders: A study of $\mathbf{4 0}$ hospitalized patients and $\mathbf{4 0}$ controls. Archives of General Psychiatry, 1967, 16, 134-145.

Hurst, M. W., Jenkins, C. D., \& Rose, R. M. The relation of psychological stress to onset of medical illness. Annual Review of Medicine, 1976, 27, 301-312.

Ilfeld, F. W. Characteristics of current social stressors. Psychological Reports, 1976, 39, 1231-1247. (a)

Ilfeld, F. W. Methodological issues in relating psychiatric symptoms to social stressors. Psychological Reports, 1976, 39, 1251-258. (b)

Ilfeld, F. W. Current social stressors and symptoms of depression. American Journal of Psychiatry, 1977, 134, 161-166.

Leff, M. J., Roatch, J.F., \& Bunney, W. E., Jr. Environmental factors preceding the onset of severe depressions. Psychiatry, 1970, 33, 293-311.

Lewinsohn, P. M. Increasing pleasant activities: $A$ treatment manual. Unpublished mimeo, University of Oregon, 1975.

Lewinsohn, P. M., Biglan, T., \& Zeiss, A. Behavioral treatment of depression. In P. Davidison (Ed.), Behavioral management of anxiety, depression, and pain. New York: Bruner/Mazel, 1976, 91-146.
Lewinsohn, P. M., \& Graf, M. Pleasant activities and depression. Journal of Consulting and Clinical Psychology, 1973, 41, 261-268.

Lewinsohn, P. M., Lobitz, W. C., \& Wilson, S. "Sensitivity" of depressed individuals to aversive stim. uli. Journal of Abnormal Psychology, 1973, 81, 259-263.

Lewinsohn, P. M., Zeiss, A. M., Zeiss, R. A., \& Haller, $\mathbf{R}$. Endogeneity and reactivity as orthogonal dimensions in depression. Journal of Nervous and Mental Disease, 1977, 164, 327-332.

Libet, J. M., Lewinsohn, P. M., \& Javorek, F. The construct of social skill: An empirical study of several behavioral measures on temporal stability, internal structure, validity, and situational generalizability. Unpublished mimeo, University of Oregon, 1973.

Lubin, B. Adjective checklists for measurement of depression. Archives of General Psychiatry. $1965,12,57-62$.

MacPhillamy, D. J., \& Lewinsohn, P. M. Depression as a function of desired and obtained pleasure. Journal of Abnormal Psychology, 1974, 83, 652-657.

Mendels, J., \& Cochrane, C. The nosology of depression: The endogenous-reactive concept. American Journal of Psychiatry, 1968, 24 (May Supplement), 1-11.

Munoz, R. F. A cognitive approach to the assessment and treatment of depression. Unpublished doctoral dissertation, University of Oregon, 1977.

Paykel, E. G., Myers, J. K., Dienelt, M. N., Klerman, G. L., Lindenthal, J. J., \& Pepper, M. P. Life events and depression: A controlled study. Archives of General Psychiatry, 1969, 21, 753-760.

Rabkin, J. G., \& Struening, E. L. Life events, stress, and illness. Science, 1976, 194, 1013-1020.

Rahe, R. H., Meyer, M., Smith, M., Kjaer, G., \& Holmes, T. H. Social stress and illness onset. Journal of Psychosomatic Research, 1964, 8, 35-44.

Rahe, R. H., McKean, J. D., \& Arthur, R. J. A longitudinal study of life change and illness patterns. Journal of Psychosomatic Research, 1967, 10, 355-366.

Schless, A. P., Schwartz, L., Goetz, C., \& Mendels, J. How depressives view the significance of life events. British Journal of Psychiatry, 1974, 125, 406-410.

Stewart, R. The differential effects of positive and negative social reinforcement upon small group behavior in depressed vs. non-depressed subjects. Unpublished masters thesis, University of Oregon, 1968. 
Thompson, K. C., \& Hendrie, H. Environmental stress in primary depressive illness. Archives of General Psychiatry, 1972, 26, 130-132.

Uhlenhuth, E. H., Lipman, R. S., Balter, M. B., \& Stern, M. Symptom intensity and life stress in the city. Archives of General Psychiatry, 1974, 31, 759-764.

Vinokur, A., \& Selzer, M. L. Desirable versus undesirable life events: Their relationship to stress and mental distress. Journal of Personality and Social Psychology, 1975, 32, 329-337.

Zeiss, A. M. Interpersonal behavior problems of the depressed: A study of outpatient treatment. Unpublished doctoral dissertation, University of Oregon, 1977.

Zeiss, A. M., Lewinsohn, P. M., \& Munoz, R. F. Nonspecific improvement effects in depression using interpersonal, cognitive, and pleasant events focused treatments. Paper presented at the Western Psychological Association meeting, San Francisco, April 1978.

\section{Acknowledgements}

This investigation was supported in part by $R e$ search Grants $M H 24477$ and $M H 28168$ from the National Institute of Mental Health. The authors wish to express their appreciation to Gayle Falk. Stephen Kikel, and Wanda Lee for their extensive help in the development of the UES and with the data collection.

\section{Author's Address}

Peter M. Lewinsohn, Department of Psychology, University of Oregon, Eugene, OR 97403. 